\title{
Genesis of diamond inclusions: An integrated cathodoluminescence (CL) and Electron backscatter defraction (EBSD) study on eclogitic and peridotitic inclusions and their diamond host.
}

\author{
Q. Van den Heuvel ${ }^{a}$, M.U. Gress ${ }^{a}$, S. Matveev ${ }^{b}$, M.R. Drury ${ }^{b}$, I.L. Chinn ${ }^{c}$, \\ G.R. Davies ${ }^{\mathrm{a}}$ \\ ${ }^{a}$ Vrije Universiteit, De Boelelaan 1085, 1081 HV Amsterdam, The Netherlands, \\ m.u.gress@vu.nl;g.r.davies@vu.nl \\ ${ }^{\mathrm{b}}$ Universiteit Utrecht, Heidelberglaan 8, 3584 CS Utrecht, The Netherland, \\ s.matveev@uu.nl,m.r.drury@uu.nl \\ ${ }^{c}$ De Beers Exploration, Johannesburg, South Africa, \\ ingrid.chinn@debeersgroup.com
}

Introduction

Diamond inclusions are potentially fundamental to understanding the formation conditions of diamond and Earth's long-term volatile cycles. In order to fully understand the implications of the mineralogical and compositional information recorded by inclusions and their host diamonds it is vital to know whether the inclusions are proto-, syn-, or epigenetic and the extent to which they have equilibrated with the diamond-forming media. In the latter context Nestola et al., (2017) have recently proposed the use of the term synchronous to cover the situation where a protogenetic phase records the time of diamond growth due to achieving equilibration with the diamond-forming media. In previous studies, the widespread assumption was made that the majority of diamond inclusions were syngenetic, based upon visual observation of cubo-octahedral morphology imposed on the inclusion (e.g., Harris \& Gurney, 1979) and crystallographic controlled relationships between host diamond and inclusions (e.g., Harris \& Gurney, 1979; Wiggers de Vries et al 2010). Recent work, however, has questioned this assumption and reported that the crystallographic relationships between inclusions and the host diamond are highly complex (Agrosì et al., 2016) with the lack of crystallographic controlled relationships between inclusions and diamonds used to question the significance of imposed diamond morphology (Nestola et al., 2014).

\section{Analytical Results}

This study presents an integrated electron backscatter diffraction (EBSD) and cathodoluminescence (CL) study of 9 diamonds containing 20 pyropes, 2 diopsides, 1 forsterite and 1 rutile from the Jwaneng and Letlhakane kimberlite clusters, Botswana. A new method was developed to image diamond growth zonation using CL and analyze the crystallographic orientation of the host diamond and the inclusions with EBSD. Diamonds were cut into plates and sequentially polished to uncover the inclusions on the plate's surface, revealing inclusions at different levels in the diamond. Imaging was performed on a JEOL JXA-8530F field emission electron probe (EMP) fitted with a panchromatic JEOL CL detector at the University of Utrecht. Imaging was done with an acceleration voltage of $10 \mathrm{kV}$ and a beam current of $5 \mathrm{pA}$. CL imaging at different depths was performed in order to produce a 3D view of diamond growth zones around the inclusions. Standard diamond polishing techniques proved too aggressive for silicate inclusions as they were damaged to such a degree that EBSD measurements on the inclusions were impossible. The inclusions were milled with a $\mathrm{Ga}^{+}$ focused ion beam (FIB) at a $12^{\circ}$ angle to clean the surface for EBSD measurements. Crystallographic orientations of diamond and the inclusions were determined using EBSD using a Helios Nanolab G3 UC. Compositions of extracted inclusions were initially determined on unpolished samples following 
the techniques of Timmerman et al. (2015) using EMP. Subsequently, inclusions were mounted in epoxy and polished to obtain core to rim compositional traverses.
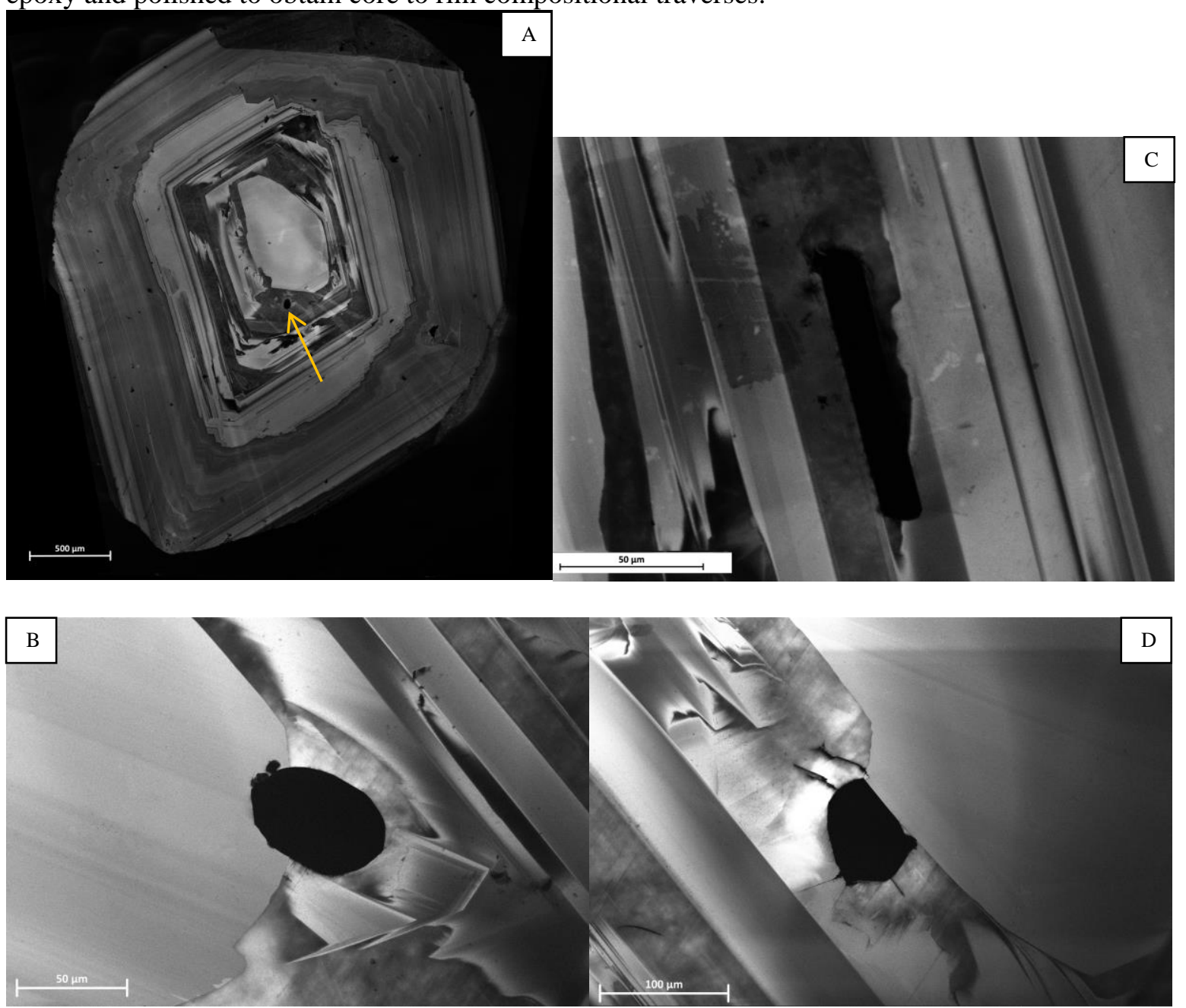

Figure 1: CL images of a central diamond plate of JW 203. A: Composite CL image of showing complex growth and resorption history. The core shows cubo-octahedral growth followed by a shift to a more octahedral growth. Orange arrow indicates position of an isolated garnet inclusion. B: close up of image A after further polishing. At greater depth the isolated garnet inclusions in image A is seen to be partly within the central core. C: Garnet inclusion parallel to diamond growth zones. D: garnet with straight face in the NE corner that nucleated on a diamond resorption surface.

\section{Discussion}

Of the 26 inclusions, 9 have an imposed cubo-octahedral morphology. Of these inclusions, 6 have faces orientated parallel to diamond growth zones (Fig. 1c) and/or appear to have nucleated on a diamond growth surface, implying syngenesis (Fig. 1d). In contrast other diamonds record resorption such that inclusions now cut through diamond growth zones making the inclusion protogenetic to later growth (Fig. 1c). In most cases, diamond growth around inclusions is not well defined due to CL haloes (Fig. 2B). A detailed TEM crystallographic and compositional study has been conducted on a transect away from an inclusion to better understand the mechanisms that control formation of the CL halo. Some inclusions cut diamond growth, suggesting syngensis (Fig 2a \& B).

Combined EBSD and CL data reveal that there is no direct correlation between the crystal orientation of silicate inclusions and the host diamond (i.e., no epitaxial growth), even when the mineral phases are of the same symmetry group. 


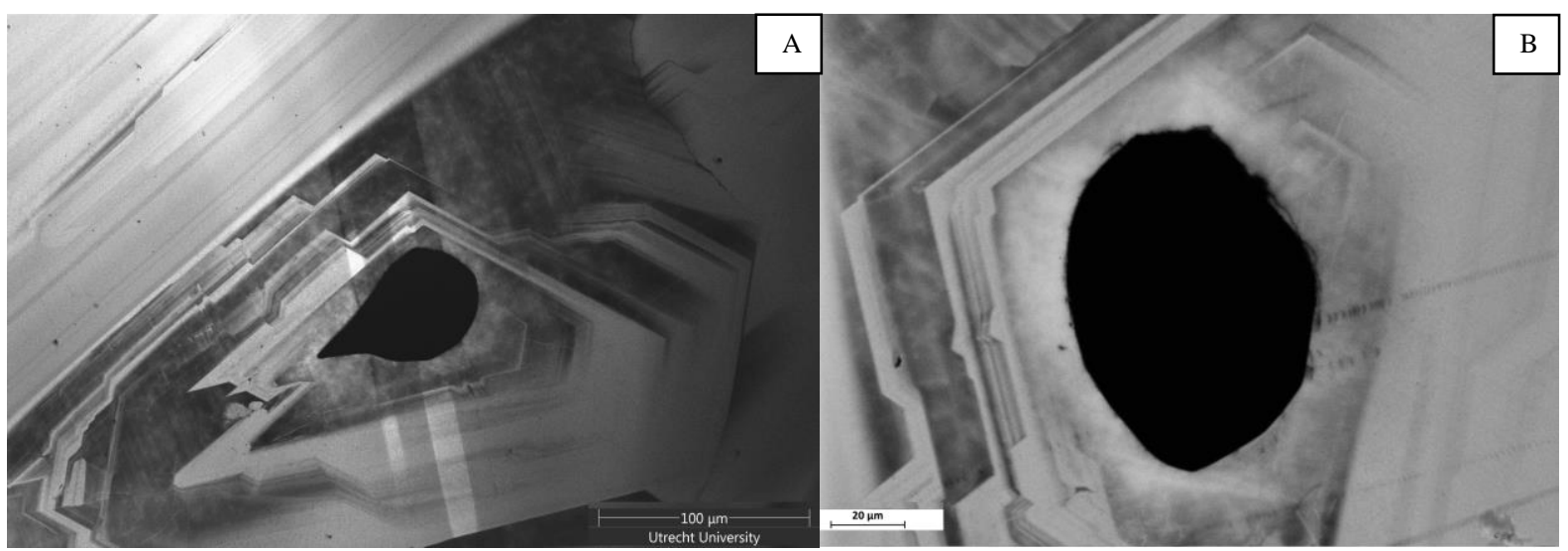

Figure 2: CL images of a central plates of JW 012. A: garnet inclusion with a shape controlled by diamond grwoth zones. Lighter grey tracks are areas of FIB milling. B: clinopyroxene partly surrounded by CL halo.

EBSD analyses on the diamonds themselves showed no angular deviations despite having multiple growth and resorption zones, implying epitaxial growth of diamond. In contrast no consistent epitaxial relationships where found between diamond and the 26 inclusions (1 crystallographic plane of a clinopyroxene was found parallel to $\{112\}$ of the host diamond).

EBSD analysis of two different diamonds with inclusion clusters in different growth zones, $\sim 400 \mu \mathrm{m}$ apart, revealed the same chemical composition and orientation for 3 inclusions, potentially implying they originated from a common larger inclusion that is protogenetic in relation to the later grown diamond.

In summary, the relationships between silicate inclusions and their host diamond reveal a multistage growth history of diamond such that individual inclusions in a single diamond may show both syngenetic and protogenetic relationships to the growth zone in which they are trapped.

\section{References}

Agrosì, G., Nestola, F., Tempesta, G., Bruno, M., Scandale, E., \& Harris, J. (2016). X-ray topographic study of a diamond from Udachnaya: Implications for the genetic nature of inclusions. Lithos, 248$251,153-159$.

Harris, J. W. \& Gurney, J. J. (1979). Inclusions in diamond. In ed J.E. Field. The Properties of Diamond, 555-591, Academic Press.

Nestola, F., Jung, H. \& Taylor, L. A. (2017). Mineral inclusions in diamonds may be synchronous but not syngenetic. Nature Communications 8, 14168.

Nestola, F., Nimis, P., Angel, R. J., Milani, S., Bruno, M., Prencipe, M., \& Harris, J. W. (2014). Olivine with diamond-imposed morphology included in diamonds. Syngenesis or protogenesis?, Int. Geol. Rev. 56, 1658-1667.

Timmerman, S. Matveev, S., Gress, M.U. \& Davies, G.R. (2015). A methodology for wavelength dispersive electron probe microanalysis of unpolished silicate minerals. Journal of Geochemical Exploration 159, 243-251.

Wiggers de Vries, D. F., Drury, M. R., de Winter, D. A. M., Bulanova, G. P., Pearson, D. G., \& Davies, G. R. (2010). Three-dimensional cathodoluminescence imaging and electron backscatter diffraction: tools for studying the genetic nature of diamond inclusions. Contributions to Mineralogy and Petrology, 161, 565-579. 